\title{
Ethnic Differences in Problem Perception: Immigrant Mothers in a Parenting Intervention to Reduce Disruptive Child Behavior
}

\author{
Patty Leijten, Maartje A. J. Raaijmakers, Bram Orobio de Castro, and Walter Matthys \\ Utrecht University
}

\begin{abstract}
Ethnic minority families in Europe are underrepresented in mental health care-a profound problem for clinicians and policymakers. One reason for their underrepresentation seems that, on average, ethnic minority families tend to perceive externalizing and internalizing child behavior as less problematic. There is concern that this difference in problem perception might limit intervention effectiveness. We tested the extent to which ethnic differences in problem perception exist when ethnic minority families engage in mental health service and whether lower levels of problem perception diminish parenting intervention effects to reduce disruptive child behavior. Our sample included 136 mothers of 3- to 8-year-olds (35\% female) from the 3 largest ethnic groups in the Netherlands (43\% Dutch; 35\% Moroccan; 22\% Turkish). Mothers reported on their child's externalizing and internalizing behavior and their perception of this behavior as problematic. They were then randomly assigned to the Incredible Years parenting intervention or a wait list control condition. We contrasted maternal reports of problem perception to teacher reports of the same children. Moroccan and Turkish mothers, compared with Dutch mothers, perceived similar levels of child behavior problems as less problematic, and as causing less impairment and burden. Teacher problem perception did not vary across children from different ethnic groups. Importantly, maternal problem perception did not affect parenting intervention effectiveness to reduce disruptive child behavior. Our findings suggest that ethnic differences in problem perception exist once families engage in treatment, but that lower levels of problem perception do not diminish treatment effects.
\end{abstract}

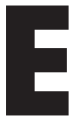

thnic minority families in Europe tend to be hard to reach for the prevention and treatment of children's behavior problems (Prinz \& Miller, 1991; Zwirs, Burger, Schulpen, \& Buitelaar, 2006). Barriers to treatment include fear of stigmatization, prior disappointing experiences, language and cultural differences, and time and financial limitations (Scheppers, Van Dongen, Dekker, Geertzen, \& Dekker, 2006; Tolan \& McKay, 1996). Moreover, ethnic minority fam-

This article was published Online First February 11, 2016.

Patty Leijten, Maartje A. J. Raaijmakers, and Bram Orobio de Castro, Department of Developmental Psychology, Utrecht University; Walter Matthys, Department of Child and Adolescent Studies, Utrecht University.

Patty Leijten is now at the Centre for Evidence-based Intervention, Department of Social Policy and Intervention, University of Oxford, and Research Institute of Child Development and Education, University of Amsterdam.

This work is financed by the Netherlands Organisation for Health Research and Development (ZonMw; Grant 157003007). Maartje Raaijmakers is involved in the dissemination and implementation of the Incredible Years parenting program in the Netherlands.

Correspondence concerning this article should be addressed to Patty Leijten, Nieuwe Achtergracht 127, 1018 WS Amsterdam, the Netherlands. E-mail: patty.leijten@spi.ox.ac.uk ilies tend to be less likely than families from the majority to consider externalizing and internalizing child behavior as problematic. These ethnic differences in reported problem perception should be distinguished from ethnic differences in reported frequency of externalizing and internalizing behavior, in which the latter reflects the mere presence of behavior rather than an interpretation of this behavior as problematic (Zwaanswijk, Verhaak, van der Ende, Bensing, \& Verhulst, 2006). Ethnic minority parents, compared with parents from the ethnic majority, report lower frequency of externalizing and internalizing behavior (Hillemeier, Foster, Heinrichs, \& Heier, 2007) and when they do report a high frequency of this behavior, they are less likely to indicate this behavior as problematic (Bevaart et al., 2012; Roberts, Alegría, Roberts, \& Chen, 2005; Weisz et al., 1988). These ethnic differences in problem perception are presumed to reflect differences in which behavior of the child parents actually perceive as problematic, as well as differences in the threshold to openly express concerns about child behavior (Ali, Liu, \& Humedian, 2004; Weisz et al., 1988).

Parental engagement in mental health services for children's behavioral problems is described as a stage-like process in which different barriers or filters must be overcome (e.g., the Levels and Filters Model; Goldberg \& Huxley, 1980, 1992; Verhulst \& Koot, 1992). Problem perception or recognition is the first step in this process. Research on ethnic differences in 
parental problem perception is generally limited to this prehelp-seeking stage (Bevaart et al., 2012; Zwirs et al., 2006). This is not surprising, as ethnic minority families are underrepresented in mental health care (Prinz \& Miller, 1991). Fortunately, researchers and practitioners have become increasingly able to reach ethnic minority families for mental health services. Examples of parenting interventions that have successfully overcome barriers to treatment and benefit ethnic minority families in Europe are the Incredible Years program in the Netherlands (Menting, Orobio de Castro, Wijngaards-de Meij, \& Matthys, 2014) and the United Kingdom (Scott, O'Connor, et al., 2010; Scott, Sylva, et al., 2010), and Parent Management Training-Oregon Model in Norway (Bjørknes, Kjøbli, Manger, \& Jakobsen, 2012). However, a critical gap exists between knowledge on problem perception by ethnic minority families and knowledge about actual treatment success. That is, we know little about the effectiveness of interventions for families with lower initial problem perception. Does their lower problem perception diminish treatment effects? The present study aims to fill this gap. We examine the extent to which ethnic differences in problem perception exist once families engage in mental health services (rather than in the pre-help-seeking stage) and whether lower rates of problem perception diminish the effectiveness of a parenting intervention to reduce children's disruptive behavior. This knowledge is vital to inform research and clinical practice about how problem perception in ethnic minority families affects treatment outcomes.

\section{Problem Perception and Intervention Effectiveness}

Does problem perception affect treatment effectiveness? Our study is among the first to examine parental problem perception in ethnic minority families in the context of a parenting intervention to reduce disruptive child behavior. One recent study showed lower levels of problem perception in ethnic minority parents who were referred for child behavior problems (Bevaart et al., 2014), but it has not yet been examined how problem perception in a multi ethnic sample actually affects parenting intervention outcomes. The mechanism behind a putative influence of problem perception on parenting intervention effectiveness may be families' motivation and readiness to change. More specifically, parents who feel that their child's behavior is not problematic may be less inclined to change their parenting behavior to change their child's behavior. In contrast, parents who feel their child's behavior is problematic may be more inclined to feel a pressing need to change. Perhaps surprisingly in this context, despite consistent findings that ethnic minority families tend to have lower levels of problem perception, at least before help seeking, families' ethnic background does not tend to affect intervention effectiveness (Menting et al., 2014; Reid, Webster-Stratton, Beauchaine, 2001). This raises the question to what extent parental problem perception in a multiethnic sample affects intervention outcomes.

\section{Parent and Teacher Problem Perception Across Domains and Settings}

Parental problem perception can vary across life domains and settings (Goodman, 1999). For example, some parents may observe inattentive or disruptive behavior to especially impact the child at school (e.g., school learning). Other parents may observe inattentive or disruptive behavior to especially impact the child at home (e.g., daily family routines). Disentangling parental problem perception into perceived problematic impact on different life domains sheds light on where precisely differences in perceived problems arise between families from different ethnic backgrounds. Concerning school, for example, ethnic minority families tend to place firm emphasis on their child's academic achievement, hoping for the child to reach high educational standards (Davis-Kean, 2005). Ethnic minority families may therefore be particularly sensitive to perceive problems in behavior that interferes with school learning. Theory and empirical findings on how families' ethnic or cultural background influences the impact families perceive of their child's behavior on different life domains is highly limited. We therefore explore ethnic differences in perceived impact on different life domains.

Teacher problem perception is the most important precursor for parental help-seeking behavior for child behavior problems after parental problem perception (Sayal, Taylor, \& Beecham, 2003). Differences between parent and teacher report of the frequency of children's problem behavior appear to reflect true differences in child behavior across settings-in addition to possible perceptual bias (De Los Reyes, 2011; Epstein et al., 2005). Teacher reported frequency of problem behavior occasionally differs across ethnic groups, but teachers generally do not perceive behavior of ethnic minority children as more problematic once the frequency of externalizing and internalizing child behavior is taken into account (Bevaart et al., 2012). In other words, whereas teachers might rate externalizing and internalizing behavior as more prevalent in ethnic minority children (Stevens \& Vollebergh, 2008; Zwirs et al., 2006), they do not perceive similar levels of behavior as more problematic in ethnic minority children than in children from the ethnic majority (Bevaart et al., 2012). However, teacher problem has never been disentangled into perceived impact of child behavior on different domains, such as classroom learning and relationships with peers. We tested the relation between children's ethnic background and teacher's problem perception, perceived impact and burden to the teacher and classroom, and contrasted these findings to maternal perception of the same children.

\section{The Present Study}

Aim of the present study was to examine ethnic differences in problem perception by mothers engaged in a parenting intervention. We (a) tested whether Turkish and Moroccan mothers in the Netherlands report similar levels of externalizing and internalizing child behavior as less problematic than Dutch mothers, (b) examined ethnic differences in reported impact of behavior across life domains and on maternal and family burden, (c) contrasted maternal perceived problems, impact and burden, to teacher perceived problems, impact and burden, and (d) examined whether lower levels of maternal problem perception at baseline diminish the effectiveness of a parenting intervention to reduce disruptive child behavior. 


\section{Method}

\section{Participants}

Our sample included 136 families. Participants of this study were enrolled in a larger study on the effectiveness of the Incredible Years parenting intervention (Leijten, Raaijmakers, Orobio de Castro, van den Ban, \& Matthys, 2015) for ethnic minority families in the Netherlands. Children were aged 4 to 8 years $(M=$ $5.61, S D=1.35 ; 35 \%$ female), and their mothers' ethnic background was Dutch (43\%), Moroccan $(35 \%)$, or Turkish $(22 \%)$. Demographics and problem behavior severity per ethnic group are presented in Table 1. Despite cultural differences, Moroccan and Turkish families included in this study (and in the wider population in the Netherlands) showed meaningful overlap in their cultural and religious norms and values. Participating Turkish and Moroccan families were from Muslim communities and the majority of them were second generation labor immigrants.

\section{Procedure}

Two recruitment strategies were used to ensure sufficient variability in families' ethnic backgrounds. First, families from two mental health care organizations who were referred for disruptive child behavior were invited to participate. Of the 52 families who were invited, 44 families participated. Eleven percent of these families were ethnic minority families.

Second, to reach ethnic minority families, we built on the experiences of earlier successful studies and on theory and empirical findings to engage ethnic minority families in treatment (Bjørknes et al., 2012; Scott, O'Connor, et al., 2010; Scott, Sylva, et al., 2010). We held coffee meetings to inform parents about the parenting intervention. We did this at elementary schools in the deprived (i.e., having relatively high poverty and unemployment rates) and multicultural neighborhoods of Utrecht, one of the Netherlands' four largest cities. In line with being approachable, parenting intervention groups in these neighborhoods were held at schools and community centers, rather than in buildings of mental health organizations. Second, parenting intervention groups were held during school hours and we offered free child care during the meetings. Third, we aimed to meet the cultural norms of Moroccan and Turkish families about relatively much segregation of activities for males and females, by organizing intervention groups for mothers only (in addition to mixed groups for mothers and fathers). Fourth, we used interpreters when needed during coffee meetings, parenting intervention meetings, and filling in questionnaires, to overcome possible language barriers. Because fear for stigmatization is typically one of the main barriers to treatment, no selection criteria based on severity of child behavior problems were used. Instead, families who showed interest for the parenting intervention were individually interviewed and invited to participate if they indicated that they perceived parenting difficulties due to oppositional child behavior. Also, because we aimed to include those families who are most notoriously hard to reach for treatment, mastering the Dutch language was not a requirement for participation and interpreters were used when needed. Around 248 families attended the coffee meetings, of which 92 Turkish families signed up for participation. Seventy-eight percent of these families were ethnic minority families. Clinical impressions were that of the families who did not sign up, some did not feel comfortable participating in the parenting intervention group, whereas others did not experience disruptive child behavior problems. Families from all ethnic backgrounds were invited to participate in the parenting intervention. Families from ethnic backgrounds other than Dutch, Moroccan, or Turkish $(N=18)$ were excluded for this particular study on problem perception to ensure sufficient sample size for each ethnic group.

\section{Design}

We used a randomized controlled design with a 2:1 ratio to randomize families to the parenting intervention or waiting list control condition (see Figure 1). For random allocation, we used a box with closed envelopes. Two thirds of the envelopes contained 'intervention condition' and one third contained 'control condition.' Researchers blind to participants drew one envelope for each

Table 1. Family Demographics per Ethnic Group

\begin{tabular}{lccc}
\hline \multicolumn{1}{c}{ Characteristic } & \begin{tabular}{c} 
Dutch \\
\multicolumn{1}{c}{$(N=59) M(S D)$}
\end{tabular} & $\begin{array}{c}\text { Moroccan } \\
=48) M(S D)\end{array}$ & $\begin{array}{c}\text { Turkish } \\
(N=29) M(S D)\end{array}$ \\
\hline Child gender (\% female) & $37 \%$ & $35 \%$ & $33 \%$ \\
Child age & $5.62(1.34)$ & $5.68(1.37)$ & $5.44(1.46)$ \\
Mother age & $34.57(5.39)$ & $34.95(6.60)$ & $32.74(4.32)$ \\
Maternal educational level* & $3.59(1.67)$ & $2.69(1.55)$ & $4.26(1.49)$ \\
Two parent family (\%) & $91 \%$ & $91 \%$ & $100 \%$ \\
Child externalizing and internalizing & & & \\
$\quad$ behavior (SDQ) & $17.09(4.55)$ & $13.57(6.15)$ & $9.63(4.73)$ \\
Mother report* & $70 \%$ & $34 \%$ & $16 \%$ \\
\% borderline or clinical & $13.69(6.10)$ & $15.13(7.31)$ & $7.35(4.50)$ \\
Teacher report* & $63 \%$ & $32 \%$ & $29 \%$ \\
\% borderline or clinical & \multicolumn{2}{c}{} \\
\hline
\end{tabular}

Note. $\mathrm{SDQ}=$ Total Problem Scale of the Strengths and Difficulties Questionnaire, 20 items on a 3-point Likert scale: $0=$ not true, $1=$ somewhat true, $2=$ certainly true. Maternal educational level was scored into 6 levels: 1 = elementary school, 2 = lower level of high school, $3=$ higher level of high school, $4=$ vocational degree, $5=$ higher education degree, $6=$ university degree.

${ }^{*} p<.05$ between Dutch versus Turkish/Moroccan families. 


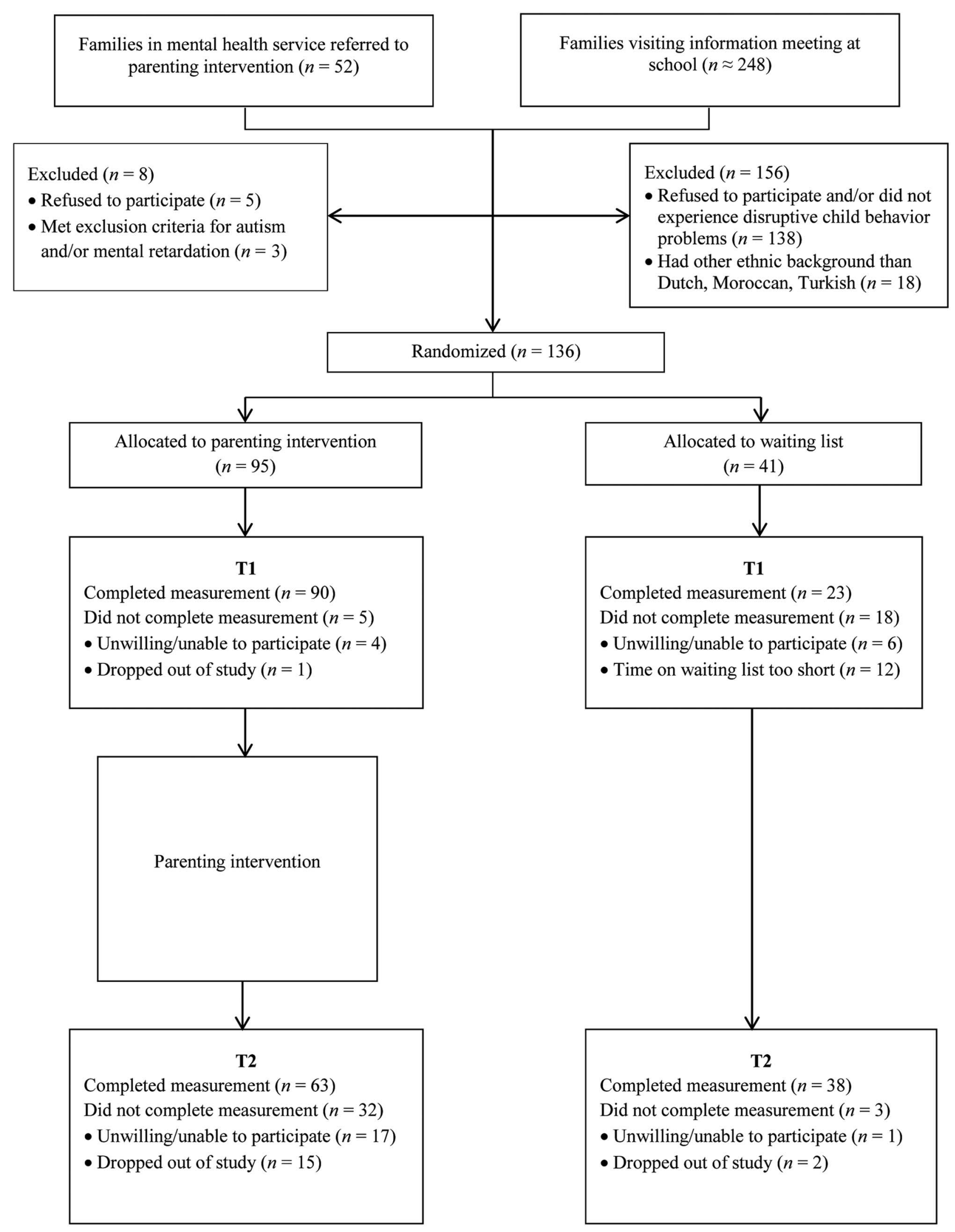

Figure 1. Participant flow. 
family who entered the study. Mothers received $€ 15$ for filling in the questionnaire. All mothers gave informed consent. The study was approved by the Medical-Ethical Committee of University Medical Centre Utrecht.

\section{Measurements}

Frequency of externalizing and internalizing child behavior. Parent and teacher versions of the Total Problem Scale of the Strengths and Difficulties Questionnaire (SDQ) were used to measure frequency of children's externalizing and internalizing behavior, before the start of the intervention (Goodman, 1997). The Total Problem Scale of the SDQ is a reliable and valid 20 -item screening measure to identify emotional and behavioral problems in children on a 3 -point scale $(0=$ not true, $1=$ somewhat true, 2 = certainly true; Goodman, 2001; van Widenfelt, Goedhart, Treffers, \& Goodman, 2003). The scale includes sum scores of the subscales conduct problems (5 items), inattention-hyperactivity (5 items), emotional problems (5 items), and peer problems ( 5 items). We first computed a mean score of the 20 items, to correct for missing item-level values. We then multiplied the mean score by 20 to calculate a sum score for the Total Problem Scale. None of the families had more than two missing items. Possible range was 0 to 20 . Higher scores reflect more externalizing and internalizing behavior. Overall internal consistency of the total problem scale was $\alpha=.77$ for mothers $(\alpha=.65$ for Dutch mothers, $\alpha=.77$ for Moroccan mothers, and $\alpha=.65$ for Turkish mothers) and $\alpha=.83$ for teachers.

Perception of problems, impact, and burden. Maternal and teachers' problem perception and perceived impact and burden were measured using the impairment items of the extended SDQ before the start of the intervention (Goodman, 1999). First, for problem perception, mothers and teachers reported the extent to which they perceived their child as showing problematic behavior difficulties on the item "do you think the child has difficulties in one or more of the following areas: emotions, concentration, behavior or the ability to get on with other people?" Second, mothers reported the perceived impact of their child's behavior on four different life domains: at home, in friendships, in learning, and in leisure activities. Teachers reported the impact of the child's behavior they perceived on two life domains: the child's peer relationships and classroom learning. Third, mothers reported whether the difficulties put a burden on her or on her family as a whole and teachers reported whether the difficulties put a burden on him/her or on the class as a whole. All impairment items were answered on the same 4-point scale $(0=$ no, $1=$ yes, minor difficulties, 2 = yes, definite difficulties, $3=$ yes, severe difficulties). Impairment items across domains correlated low to moderately (between $r=.18$ and $r=.58$ ) and were therefore analyzed separately.

Disruptive child behavior. Effectiveness of the parenting intervention to reduce children's reduced disruptive behavior was measured using the Intensity Scale of the Eyberg Child Behavior Inventory (ECBI; Eyberg \& Ross, 1978) before and immediately after the intervention. The ECBI is a widely used 36-item questionnaire for parent-reported frequency of disruptive child behaviors on a 7-point Likert scale $(1=$ never, $2-3=$ seldom, $4=$ sometimes, $5-6=$ often, $7=$ always $)$. Sample items include "refuses to do chores when asked" and "has temper tantrums." We first computed mean scores, to correct for missing item-level values. We then multiplied the mean score by 36 to calculate a sum score for the Intensity Scale. None of the families had more than four missing items on the total problem scale. Possible range was 36 to 252 . Higher scores reflect more disruptive child behavior. Internal consistency was $\alpha=.92(\alpha=.91$ for Dutch mothers, $\alpha=.92$ for Moroccan mothers, and $\alpha=.85$ for Turkish mothers).

\section{Parenting Intervention}

We used the BASIC Incredible Years videotape modeling parent intervention (Webster-Stratton, 2001). This intervention is designed for the treatment or prevention of disruptive child behavior in young children (age 2 to 8). Groups of 8 to 15 parents meet weekly for 12 to 18 two hour sessions. The program is based on (social) learning theory and attachment theory principles and includes teaching parents parent-child play, praise and rewards, coaching of social, emotional and academic skills, effective limit setting, and handling misbehavior (e.g., ignore and time-out techniques). Group leaders use a collaborative approach in which parents are seen as the expert on their own children. All sessions were videotaped and discussed by the group leaders in biweekly supervision meetings to monitor program fidelity. At least one of the two group leaders of each group was Incredible Years certified. Parents attended on average $78 \%$ of the sessions. Dutch, Moroccan, and Turkish mothers showed the same attendance rates ( $p=$ .33). Further details of the program and the main effects of Incredible Years to improve parenting behavior and reduce disruptive child behavior in this sample are reported in (Leijten et al., 2015).

\section{Data Analysis}

First, we used univariate analysis of covariance (ANCOVA) to test whether Dutch, Moroccan, and Turkish mothers had different levels of problem perception. Including frequency of externalizing and internalizing child behavior as a covariate in the analysis of variance enabled us to specifically test the extent mothers perceive the behavior they observe in their children as problematic, while controlling for actual behavior. Second, for mothers who perceived at least minor problems (i.e., a score of at least 1 on the $0-3$ scale of problem perception), we used additional ANCOVAs to examine whether ethnic differences in perceived impact of child behavior varied across life domains (home, friendships, school, leisure time) and perceived maternal or family burden. To control for inflation of error rate due to multiple significance tests, we used (alpha $X$ $i / m)$ as the significance level for each of these tests, where alpha was the target error rate of $.05, i$ was the ordered position of the $i$ th largest $p$ value associated with an individual test, and $m$ was the number of significance tests (cf. Benjamini \& Hochberg, 1995). Third, we repeated these analyses for teacher problem perception, perceived impact on different life domains (classroom learning and peer relations), and perceived teacher or classroom burden. We controlled for teacher reported frequency of externalizing and 
internalizing child behavior and again used the Benjamini and Hochberg (1995) method to control for inflation of error rate due to multiple significance tests. Fourth, we used a two-way ANCOVA to examine whether maternal problem perception influenced (i.e., functioned as a moderator on) the effects of the parenting intervention to reduce disruptive child behavior. Following intention to treat principles, we included data from all 136 families in this analysis, using multiple imputation (Little \& Rubin, 2002) to account for missing data.

\section{Results}

\section{Preliminary Analyses}

Mother-reported frequency of externalizing and internalizing children's problem behavior varied across ethnic groups, $F(2,109)=$ 10.83, $p<.001$. Dutch mothers reported the highest frequency, followed by Moroccan mothers. Turkish mothers reported the lowest frequency. Teacher-reported frequency of child behavior showed a similar pattern, $F(2,106)=4.55, p<.05$. Teachers reported higher frequency of problem behavior in Dutch and Moroccan children than in Turkish children. Almost all teachers had Dutch ethnic backgrounds $(>90 \%)$, we therefore did not include teacher ethnicity in our analyses. As expected, frequency of children's problem behavior was higher in children recruited in outpatient psychiatric clinics, compared to children recruited in schools, $F(1,127)=25.10, p<.001$.

Of the relevant family characteristics, only maternal educational level varied across ethnic groups (see Table 1). Dutch and Turkish mothers had on average higher educational levels than Moroccan mothers $(\beta=.34, p<.01$ and $\beta=.43, p<.001$, respectively). This variable was therefore included as a covariate-in addition to frequency of child behavior-in all further analyses on ethnic differences in problem perception. Assumptions of homogeneity of variances and homogeneity of regression slopes were met ( $p \mathrm{~s}>$ .52 ) and allowed us to use ANCOVAs for our primary analyses.
There were no differences in demographic characteristics or baseline scores on the Eyberg Child Behavior Inventory between families in the intervention condition and families in the control condition (see Table 3). Seventeen percent of the families had missing data at baseline (see Figure 1). Most of these families did not drop out of the study, but were unable to fill in questionnaires at the allocated time. Twenty-four percent of the families had missing data at post intervention measurement. Attrition rates did not differ between recruitment strategies or between ethnic groups.

\section{Primary Analyses}

Dutch, Moroccan, and Turkish mothers differed in the extent to which they perceived children's externalizing and internalizing behavior as problematic, even when controlling for the actual frequency of the behavior, $F(2,94)=9.41, p<.001, d=.91$ (see Table 2). Moroccan and Turkish mothers, compared with Dutch mothers, perceived similar levels of externalizing and internalizing behavior as less problematic. There was no difference in problem perception between Moroccan and Turkish mothers.

Adding referral process $(1=$ referred; $0=$ not referred $)$ as a covariate to the analysis of ethnicity and problem perception did not change the results. If anything, adding referral process as a covariate increased the significance level of the effect of ethnicity on problem perception, confirming the robustness of this finding. Although Moroccan and Turkish mothers were less often referred for disruptive child behavior (i.e., they were more often actively recruited for participation in the parenting intervention than Dutch mothers), differences in referral process thus did not influence the effects of ethnicity on problem perception.

For mothers who perceived at least minor problems in their child's behavior (i.e., a score of at least 1 on the $0-4$ scale), we examined ethnic difference in perceived impact of the child's behavior on specific life domains (home, friendships, school, leisure time) and maternal and family burden. Dutch, Moroccan, and Turkish mothers differed in the extent to which they perceived

Table 2. Perceived Problems, Impairment, and Burden per Ethnic Group at Baseline-Corrected for Frequency of Child Behavior and Maternal Educational Level

\begin{tabular}{lccc}
\hline \multicolumn{1}{c}{ Measure } & $\begin{array}{c}\text { Dutch } \\
(N=59) M(S D)\end{array}$ & $\begin{array}{c}\text { Moroccan } \\
(N=48) M(S D)\end{array}$ & $\begin{array}{c}\text { Turkish } \\
(N=29) M(S D)\end{array}$ \\
\hline Maternal perception & & & $.92(.86)$ \\
Problem perception* & $1.77(.80)$ & $.85(.82)$ & $.50(.71)$ \\
$\quad$ Impairment at home* & $1.51(.91)$ & $.88(.88)$ & $.40(.70)$ \\
$\quad$ Impairment on friendships* & $1.21(.86)$ & $.56(.75)$ & $.60(.97)$ \\
$\quad$ Impairment on learning at school & $1.41(.91)$ & $1.15(.96)$ & $.40(.70)$ \\
Impairment on leisure activities & $1.21(.73)$ & $.79(.88)$ & $.82(1.03)$ \\
$\quad$ Burden for mother/family* & $1.89(.82)$ & $1.21(.82)$ & $1.18(.66)$ \\
Teacher perception & & & $1.64(.89)$ \\
Problem perception & $1.54(.85)$ & $1.25(1.09)$ & $1.14(.63)$ \\
$\quad$ Impairment on learning at school & $1.54(.94)$ & $1.13(1.08)$ & $1.51(.83)$ \\
Impairment on peer contact & $1.52(1.06)$ & $1.48(1.00)$ & \\
Burden for teacher/class & $1.27(1.00)$ & $1.28(1.07)$ & \\
\hline
\end{tabular}

Note. All items were answered on a 0-4 Likert scale. Problem perception item: $0=$ no, $1=$ yes, minor difficulties, $2=$ yes, definite difficulties, $3=$ yes, severe difficulties. Impairment and burden items: $0=$ not at all, 1 = only a little, $2=$ a medium amount, $3=$ a great deal .

${ }^{*} p<.05$ between Dutch versus Moroccan and Turkish families. 
Table 3. Demographic Characteristics and Child Behavior Scores of Families in the Intervention and Control Condition

\begin{tabular}{lcc}
\hline \multicolumn{1}{c}{ Characteristic } & $\begin{array}{c}\text { Intervention } \\
(N=95)\end{array}$ & $\begin{array}{c}\text { Control } \\
N=41) \\
M(S D)\end{array}$ \\
\hline Child gender (\% female) & $30 \%$ & $40 \%$ \\
Child age & $5.71(1.37)$ & $5.49(1.22)$ \\
Mother age & $34.52(5.88)$ & $33.89(5.65)$ \\
Maternal educational level & $3.23(1.64)$ & $3.34(1.70)$ \\
Ethnic background (\% minority) & $55 \%$ & $50 \%$ \\
Disruptive Child Behavior (ECBI) & \\
$\quad$ Pretest & & \\
$\quad$ Posttest & $122.25(30.91)$ & $131.06(35.33)$ \\
\hline
\end{tabular}

${ }^{a}$ ECBI scores were based on the 36-item Intensity Scale rating the frequency of disruptive behaviors on a 7-point Likert Scale: $1=$ never, 2-3 = seldom, $4=$ sometimes, $5-6=$ often, 7 = always. Maternal educational level was scored into 6 levels: $1=$ elementary school, 2 = lower level of high school, 3 = higher level of high school, $4=$ vocational degree, $5=$ higher education degree, $6=$ university degree.

$* p<.05$ between intervention and control group.

negative impact of their children's behavior on two out of four life domains (home and friendships), and on perceived maternal and family burden. Moroccan and Turkish mothers, compared to Dutch mothers, perceived similar frequency of externalizing and internalizing behavior to have less impact on children's functioning at home and in friendships, $F(2,78)=4.28, p<.05, d=.66$, and $F(2,78)=3.88, p<.05, d=.63$, respectively, and perceived less maternal and family burden as a result of their child's behavior, $F(2,78)=3.86, p<.05, d=.63$. There were no differences in perceived impact between Moroccan and Turkish mothers of the child's behavior at home and in friendships, or in perceived maternal and family burden. Also, there were no differences between mothers from different ethnic backgrounds in perceived impact of child behavior on children's school learning and leisure time $(p>$ .19).

In contrast to maternal perception, teacher perception of problems, impact, and burden did not depend on children's ethnic backgrounds. Teachers perceived similar frequency of externalizing and internalizing behavior as equally problematic across children from different ethnic groups, $F(2,90)=1.56, n s$, and as equally affecting children's classroom learning, relations with peers and teacher, or class burden equally across children from different ethnic groups $(p>.14)$.

Finally, we examined the extent to which differences in maternal problem perception influenced the effectiveness of the parenting intervention to reduce disruptive child behavior. There was a main effect of condition (parenting intervention vs. control) on disruptive child behavior, $F(2,104)=7.03, p<.01, d=.61$, indicating that the parenting intervention reduced disruptive child behavior in our multiethnic sample. The effect of the intervention on disruptive child behavior did not differ by ethnic group (ethnic minority vs. ethnic majority, $F(3,102)=0.77, n s)$. More importantly, the condition $\times$ level of problem perception interaction term was not significant, $F(3,102)=2.14, n s$, indicating that problem perception did not influence the effects of the parenting intervention to reduce disruptive child behavior. Lower levels of problem perception in our multiethnic sample thus did not diminish parenting intervention effectiveness.

\section{Discussion}

Ethnic minority families in Europe are hard to reach for the prevention and treatment of child behavior disorders. One of the reasons for their lack of engagement in mental health services is presumed to be their tendency to perceive, compared with families from the ethnic majority, children's externalizing and internalizing behavior as less problematic (Bevaart et al., 2012; Zwirs et al., 2006). Knowledge is lacking on whether these ethnic differences in problem perception are limited to the pre-help-seeking process, or also exist once families engage in help. Moreover, knowledge is lacking whether levels of problem perception in ethnic minority families diminish the effectiveness of mental health services. We examined ethnic differences in problem perception by mothers engaged in a parenting intervention and the extent to which problem perception affected parenting intervention effectiveness to reduce disruptive child behavior.

Moroccan and Turkish mothers, compared with Dutch mothers, perceived a similar frequency of externalizing and internalizing child behavior as less problematic. This finding is in accordance with studies on ethnic differences in problem perception in families who are not engaged in an intervention (Bevaart et al., 2012). More specifically, compared with Dutch families, Moroccan and Turkish mothers perceived less negative impact of their children's behavior in the home and in friendships, and perceived less personal and family burden as a result of their children's behavior. More specifically, this finding shows that also when ethnic minority families engage in treatment and thus feel the need to support their parenting situation, they report externalizing and internalizing child behavior as less problematic, and to bring along less impact and personal burden compared with families from the ethnic majority. This finding was the similar for Moroccan and Turkish families, which is in line with previous research (Bevaart et al., 2012)

There may be several possible explanations for this finding. First, religious or traditional values such as valuing collectivism and conformity, rather than individualism and authenticity, may influence how parents perceive atypical child behavior and the extent to which they feel personally impacted by this behavior (Ali et al., 2004; Weisz et al., 1988). Based on this cultural difference, that is shared by Moroccan and Turkish parents versus Dutch parents, Moroccan and Turkish mothers may for example be more inclined to focus on conforming to their child's needs, rather than on feeling personally burdened. Second, families from ethnic minority groups who fear stigmatization may be more reluctant to acknowledge that their child has behavioral difficulties. Third, most ethnic minority families in our sample lived in deprived neighborhoods and had lower socioeconomic status. Mothers may be less focused on the difficulties their child experiences, because of these other stressors. Stress is known to reduce parental sensitivity to children's behavior (Paulussen-Hoogeboom, Stams, Hermanns, \& Peetsma, 2008).

Mothers from different ethnic backgrounds did not differ in perceived impact of child behavior on children's learning in schoo and leisure time. Thus, for the same levels of child behavior problems, mothers across ethnic groups perceived similar impact of this behavior on children's learning in school and leisure time. Ethnic minority families are known to place strong emphasis on children's academic achievement (Davis-Kean, 2005). Although 
this did not led to more perceived impact in this study, it may explain why ethnic minority families perceived similar (rather than less) impact of child behavior on school learning.

Teachers' level of perceived problems did not depend on children's ethnic background. Teachers perceived similar frequency of externalizing and internalizing child behavior to result in equal problems, impact, and burden for children across ethnicities alike. This finding is in accordance with previous studies that indicate that although teachers tend to report more frequent externalizing and internalizing behavior in ethnic minority children (Stevens \& Vollebergh, 2008; Zwirs et al., 2006), they perceive similar levels of this behaviors as equally problematic for children across ethnic groups (Zwirs et al., 2006).

Differences in problem perception did not affect the effectiveness of the parenting intervention to reduce disruptive child behavior. Although Moroccan and Turkish mothers perceived externalizing and internalizing child behavior as less problematic, children of mothers with lower levels of problem perception benefited as much from the intervention as children of mothers with higher levels of problem perception. This finding is in line with research showing that parents' ethnic background rarely influences parenting intervention effectiveness (Reid et al., 2001; Scott, O'Connor, et al., 2010). Perhaps ethnic differences in parental problem perception reflect ingrained cultural differences in the perception of child behavior, rather than cues of differential motivation for help once it is offered in a way that overcomes key barriers to treatment (e.g., fear for stigma, cultural differences, and money). Please see Leijten et al. (2015) for more detailed description of how key barriers to treatment were overcome in this intervention, and for full outcomes of the parenting intervention. The findings that ethnicity and problem perception did not affect intervention success indicate that parenting interventions seem to benefit families from a wide range of backgrounds equally. Based on our findings, it thus seems unjustified to presume that parenting interventions will be less effective among ethnic minority families who perceive lower levels of behavior problems in their children.

Some limitations of this study merit consideration. First, we replicated ethnic differences in problem perception in the general population in a sample of parents engaged in a parenting intervention. We were not able to explain why ethnic differences in problem perception and observed impact and burden existed. For a more stringent test of the stability of ethnic differences in problem perception before and after help seeking, and through the process of an intervention, studies are needed that follow and measure problem perception at different stages of the help-seeking process. Second, our sample sizes were relatively small, especially for mothers of Turkish children. This is not surprising, as our focus was on including hard to reach families in a parenting intervention that typically do not seek for or accept mental health treatment. We were successful to the extent that we were able to reach families with on average subclinical levels of child behavior of whom many hardly mastered the Dutch language (30\% indicated no mastering at all or only reasonable mastering of Dutch). However, our small groups limited the possibility to find more subtle differences between and within ethnic groups, such as how differences in educational level or level of integration into Dutch society within ethnic groups might affect problem perception and treatment outcomes. Third, although including the referral process as a control variable did not affect our results on maternal problem perception, we consider it important to note that we cannot exclude the possibility that the lower levels of problem perception in ethnic minority families are somewhat related to our recruitment strategy and that actively recruited families had different motivations for participation (e.g., learning more about daily parenting struggles) than referred families (e.g., receiving help to reduce problematic behavior). This said, in the Netherlands - and many Western countries alike-ethnic minority families are underrepresented in voluntary mental health care (Pels \& Vollebergh, 2006), which is why the second recruitment strategy was necessary. Also, teachers reported subclinical levels of externalizing and internalizing behavior in most children (see Bourdon, Goodman, Rae, Simpson, \& Koretz, 2005, for SDQ norm scores), suggesting that at least some problematic behaviors were present in the actively recruited families. Please note that we controlled for differences in frequency of externalizing and internalizing child behavior.

Knowledge on cultural differences in problem perception is important for clinical practice, as clinicians' awareness of these differences may increase understanding individual families' perceptions of child behavior and clinician-client alliance during the process of referral and intervention. Future research is needed to improve our understanding of the processes of the perception of children's behavior by parents across ethnic backgrounds and of the ways in which parents report their perceptions. This knowledge is vital for understanding the concept of problem perception across cultures.

This study shows that Moroccan and Turkish families in the Netherlands perceive externalizing and internalizing behavior in children as less problematic than Dutch families. However, lower levels of problem perception did not result in smaller effects of a parenting intervention on reduced disruptive child behavior. These findings suggest that ethnic differences in problem perception exist in families engaged in a parenting intervention, but that lower levels of problem perception do not diminish intervention effects.

Keywords: disruptive child behavior; ethnicity; parenting intervention; problem perception

\section{References}

Ali, S. R., Liu, W. M., \& Humedian, M. (2004). Islam 101: Understanding the religion and therapy implications. Professional Psychology: Research and Practice, 35, 635-642. http://dx.doi.org/10.1037/0735-7028 .35 .6 .635

Benjamini, Y., \& Hochberg, Y. (1995). Controlling the false discovery rate: A practical and powerful approach to multiple testing. Journal of the Royal Statistical Society Series A (Statistics in Society), 57, 289300.

Bevaart, F., Mieloo, C. L., Donker, M. C., Jansen, W., Raat, H., Verhulst, F. C., \& van Oort, F. V. (2014). Ethnic differences in problem perception and perceived need as determinants of referral in young children with problem behaviour. European Child \& Adolescent Psychiatry, 23, 273-281.

Bevaart, F., Mieloo, C. L., Jansen, W., Raat, H., Donker, M. C. H., Verhulst, F. C., \& van Oort, F. V. A. (2012). Ethnic differences in problem perception and perceived need for care for young children with problem behaviour. Journal of Child Psychology and Psychiatry, 53, 1063-1071. http://dx.doi.org/10.1111/j.1469-7610.2012.02570.x

Bjørknes, R., Kjøbli, J., Manger, T., \& Jakobsen, R. (2012). Parent training among ethnic minorities: Parenting practices as mediators of change in child conduct problems. Family Relations, 61, 101-114. http://dx.doi .org/10.1111/j.1741-3729.2011.00683.x 
Bourdon, K. H., Goodman, R., Rae, D. S., Simpson, G., \& Koretz, D. S. (2005). The Strengths and Difficulties Questionnaire: U.S. normative data and psychometric properties. Journal of the American Academy of Child \& Adolescent Psychiatry, 44, 557-564. http://dx.doi.org/10.1097/ 01.chi.0000159157.57075.c8

Davis-Kean, P. E. (2005). The influence of parent education and family income on child achievement: The indirect role of parental expectations and the home environment. Journal of Family Psychology, 19, 294-304. http://dx.doi.org/10.1037/0893-3200.19.2.294

De Los Reyes, A. (2011). Introduction to the special section: More than measurement error: Discovering meaning behind informant discrepancies in clinical assessments of children and adolescents. Journal of Clinical Child and Adolescent Psychology, 40, 1-9. http://dx.doi.org/10 $.1080 / 15374416.2011 .533405$

Epstein, J. N., Willoughby, M., Valencia, E. Y., Tonev, S. T., Abikoff, H. B., Arnold, L. E., \& Hinshaw, S. P. (2005). The role of children's ethnicity in the relationship between teacher ratings of attention-deficit/ hyperactivity disorder and observed classroom behavior. Journal of Consulting and Clinical Psychology, 73, 424-434. http://dx.doi.org/10 .1037/0022-006X.73.3.424

Eyberg, S. M., \& Ross, A. W. (1978). Assessment of child behavior problems: The validation of a new inventory. Journal of Clinical Child Psychology, 7, 113-116. http://dx.doi.org/10.1080/15374417809532835

Goldberg, D., \& Huxley, P. (1980). Mental illness in the community: The pathway to psychiatric care. London, UK: Tavistock.

Goldberg, D., \& Huxley, P. (1992). Common mental disorders: A biosocial model. London, UK: Routledge.

Goodman, R. (1997). The Strengths and Difficulties Questionnaire: A research note. Journal of Child Psychology and Psychiatry, 38, 581586. http://dx.doi.org/10.1111/j.1469-7610.1997.tb01545.x

Goodman, R. (1999). The extended version of the Strengths and Difficulties Questionnaire as a guide to child psychiatric caseness and consequent burden. Journal of Child Psychology and Psychiatry, 40, 791799. http://dx.doi.org/10.1111/1469-7610.00494

Goodman, R. (2001). Psychometric properties of the strengths and difficulties questionnaire. Journal of the American Academy of Child \& Adolescent Psychiatry, 40, 1337-1345. http://dx.doi.org/10.1097/ 00004583-200111000-00015

Hillemeier, M. M., Foster, E. M., Heinrichs, B., \& Heier, B., \& the Conduct Problems Prevention Research Group. (2007). Racial differences in parental reports of attention-deficit/hyperactivity disorder behaviors. Journal of Developmental and Behavioral Pediatrics, 28, 353361. http://dx.doi.org/10.1097/DBP.0b013e31811ff8b8

Leijten, P., Raaijmakers, M. A. J., Orobio de Castro, B., van den Ban, E., \& Matthys, W. (2015). Effectiveness of the Incredible Years parent training for low socioeconomic status and ethnic minority families. Journal Clinical Child and Adolescent Psychology, Advance online publication. http://dx.doi.org/10.1080/15374416.2015.1038823

Little, R. J. A., \& Rubin, D. B. (2002). Statistical analysis with missing data. Hoboken, NJ: Wiley.

Menting, A. T., Orobio de Castro, B., Wijngaards-de Meij, L. D., \& Matthys, W. (2014). A trial of parent training for mothers being released from incarceration and their children. Journal of Clinical Child and Adolescent Psychology, 43, 381-396.

Paulussen-Hoogeboom, M. C., Stams, G. J. J., Hermanns, J. M., \& Peetsma, T. T. (2008). Relations among child negative emotionality, parenting stress, and maternal sensitive responsiveness in early childhood. Parenting: Science and Practice, 8, 1-16. http://dx.doi.org/10 $.1080 / 15295190701830656$

Pels, T., \& Vollebergh, W. (Eds.) (2006). Diversiteit in opvoeding en ontwikkeling. Een overzicht van recent onderzoek in Nederland [Diversity in parenting and child development: An overview of recent findings in the Netherlands]. Amsterdam, the Netherlands: Aksant.
Prinz, R. J., \& Miller, G. E. (1991). Issues in understanding and treating childhood conduct problems in disadvantaged populations. Journal of Clinical Child Psychology, 20, 379-385. http://dx.doi.org/10.1207/ s15374424jccp2004_6

Reid, M. J., Webster-Stratton, C., \& Beauchaine, T. P. (2001). Parent training in head start: A comparison of program response among African American, Asian American, Caucasian, and Hispanic mothers. Prevention Science, 2, 209-227. http://dx.doi.org/10.1023/A:1013618309070

Roberts, R. E., Alegría, M., Roberts, C. R., \& Chen, I. G. (2005). Mental health problems of adolescents as reported by their caregivers: A comparison of European, African, and Latino Americans. The Journal of Behavioral Health Services \& Research, 32, 1-13. http://dx.doi.org/10 .1007/BF02287324

Sayal, K., Taylor, E., \& Beecham, J. (2003). Parental perception of problems and mental health service use for hyperactivity. Journal of the American Academy of Child \& Adolescent Psychiatry, 42, 1410-1414. http://dx.doi.org/10.1097/00004583-200312000-00007

Scheppers, E., van Dongen, E., Dekker, J., Geertzen, J., \& Dekker, J. (2006). Potential barriers to the use of health services among ethnic minorities: A review. Family Practice, 23, 325-348. http://dx.doi.org/ 10.1093/fampra/cmi113

Scott, S., O'Connor, T. G., Futh, A., Matias, C., Price, J., \& Doolan, M (2010). Impact of a parenting program in a high-risk, multi-ethnic community: The PALS trial. Journal of Child Psychology and Psychiatry, 51, 1331-1341. http://dx.doi.org/10.1111/j.1469-7610.2010.02 302.x

Scott, S., Sylva, K., Doolan, M., Price, J., Jacobs, B., Crook, C., \& Landau, S. (2010). Randomised controlled trial of parent groups for child antisocial behaviour targeting multiple risk factors: The SPOKES project. Journal of Child Psychology and Psychiatry, 51, 48-57. http://dx.doi .org/10.1111/j.1469-7610.2009.02127.x

Stevens, G. W., \& Vollebergh, W. A. (2008). Mental health in migrant children. Journal of Child Psychology and Psychiatry, 49, 276-294. http://dx.doi.org/10.1111/j.1469-7610.2007.01848.x

Tolan, P. H., \& McKay, M. M. (1996). Preventing serious antisocia behavior in inner-city children: An empirically based family intervention program. Family Relations, 45, 148-155. http://dx.doi.org/10.2307/ 585285

van Widenfelt, B. M., Goedhart, A. W., Treffers, P. D., \& Goodman, R. (2003). Dutch version of the Strengths and Difficulties Questionnaire (SDQ). European Child \& Adolescent Psychiatry, 12, 281-289. http:// dx.doi.org/10.1007/s00787-003-0341-3

Verhulst, F. C., \& Koot, J. M. (1992). Child psychiatric epidemiology: Concepts, methods and findings. Beverly Hills, CA: Sage. http://dx.doi org/10.4135/9781483325804

Webster-Stratton, C. (2001). The Incredible Years: Parents and Children Videotape Series. A parenting course (BASIC). Seattle, WA: Incredible Years.

Weisz, J. R., Suwanlert, S., Chaiyasit, W., Weiss, B., Walter, B. R., \& Anderson, W. W. (1988). Thai and American perspectives on over- and undercontrolled child behavior problems: Exploring the threshold model among parents, teachers, and psychologists. Journal of Consulting and Clinical Psychology, 56, 601-609. http://dx.doi.org/10.1037/0022-006X .56 .4 .601

Zwaanswijk, M., Verhaak, P. F. M., van der Ende, J., Bensing, J. M., \& Verhulst, F. C. (2006). Change in children's emotional and behavioural problems over a one-year period: Associations with parental problem recognition and service use. European Child \& Adolescent Psychiatry 15, 127-131. http://dx.doi.org/10.1007/s00787-005-0513-4

Zwirs, B. W. C., Burger, H., Schulpen, T. W. J., \& Buitelaar, J. K. (2006). Different treatment thresholds in non-Western children with behavioral problems. Journal of the American Academy of Child \& Adolescent Psychiatry, 45, 476-483. http://dx.doi.org/10.1097/01.chi.0000192251 $.46023 .5 \mathrm{a}$ 